\title{
Case for Dynamic Reconfigurability in Access Networks
}

\author{
Rajeev Roy, Student Member, IEEE \\ Telecommunication Engineering \\ 8202 Hogekamp, University of Twente, PO 217 \\ Enschede, $7500 \mathrm{AE}$, Netherlands \\ r.roy@ewi.utwente.nl
}

\author{
Wim van Etten, Senior Member, IEEE \\ Telecommunication Engineering \\ 8214 Hogekamp, University of Twente, PO 217 \\ Enschede, 7500 AE, Netherlands \\ w.c.vanEtten@ewi.utwente.nl
}

\begin{abstract}
The paper discusses the merits of having a reconfigurable access network. The network is viewed as a stack of logical PONs in which bandwidth can be redistributed on an inter-PON scale. The redistribution allows for optimal distribution of bandwidth to the end user.
\end{abstract}

Keywords- PON; EPON; GPON ; WDM PON; dynamic reconfiguration; OLT; ONU; access networks

\section{INTRODUCTION}

The BBPhotonics (BBP) project under the consortium of Freeband projects looks into the design of an extended access network. The network is a reconfigurable and resilient multiwavelength photonic access network. The network is expected to cater to multiple communities which are geographically spaced out. The paper discusses the salient features of the network and presents a case to have reconfigurability in access networks. Section II introduces the network design and presents the network as a conceptual stack of quasi independent PONs. Section III presents a study into typical bandwidth requirements foreseen in the access in the near future. Section IV presents two network profiles which are used to discuss the merits of a reconfigurable network. Section V describes performance metrics of providing bandwidth to the user by means of a static network configuration and then comparing it with the dynamic network configuration presented.

\section{NETWORK ARCHITECTURE}

\section{A. Physical Design}

Fig. 1 illustrates the network schematically. The drop fiber connection from the Head End (HE) to the first Remote Node (RN) is presumed to be $20 \mathrm{~km}$. The inter RN spacing is again taken to be nominally $20 \mathrm{~km}$. The drop fibers from the RN to the Customer Premises Equipment (CPE), which houses the Optical Network Unit (ONU), is taken as $5 \mathrm{~km}$. The motivation for the parameters so chosen is to provide a region wide access network with a central office location housing the HE. The RNs house micro-ring resonator [1] based Reconfigurable Optical Add Drop Multiplexers (ROADMs). The ROADMs can be used to have add/drop of any wavelength towards any of its ports. The RNs thus act as the optical splitters as in

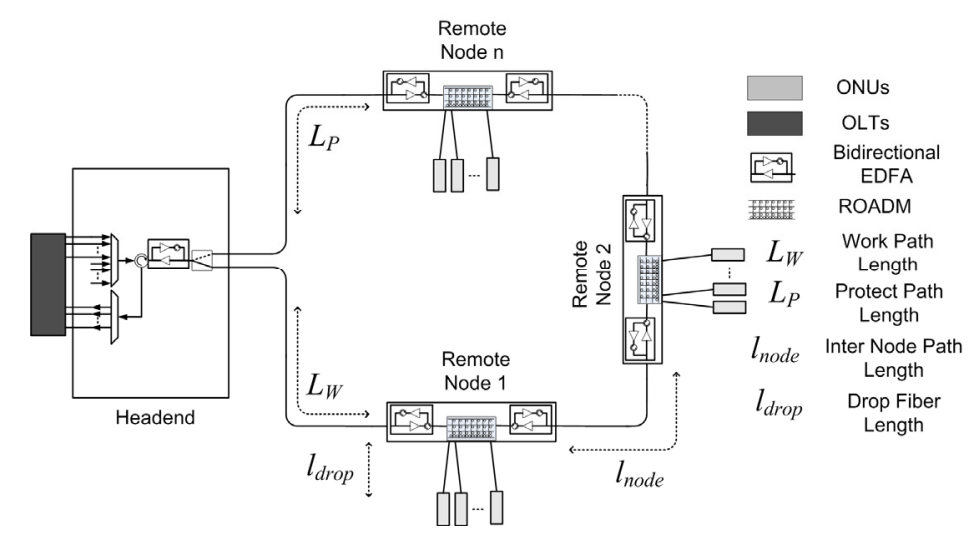

Figure 1. Schematic of BBPhotonics Network

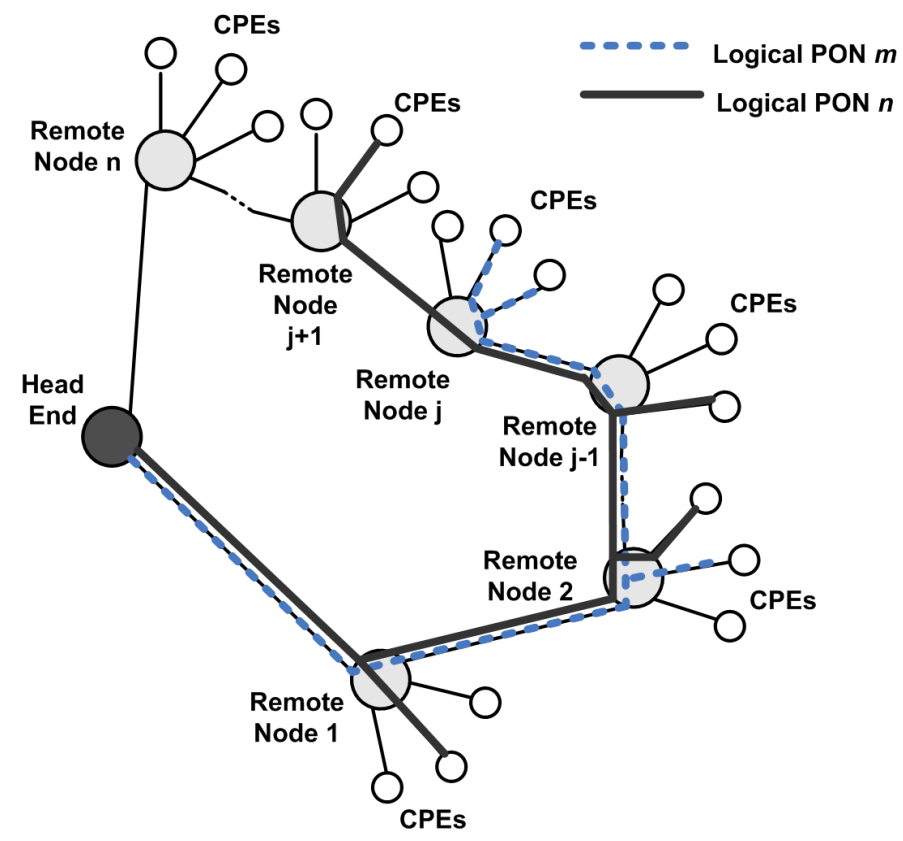

Figure 2 . Logical connection between HE and CPEs, two logical PONs are illustrated

equivalent legacy Passive Optical Networks (PON)s.

Work is funded by the Dutch Ministry of Economic Affairs under the contract BSIK 03025 


\section{B. Network Topology}

The logical network topology retains a tree architecture as in legacy PONs. Fig. 2 illustrates the logical connectivity between the HE and a set of CPEs connected to a diverse RNs. Each $\mathrm{RN}$ has two or more fiber connections and thus each such RN has fiber connectivity for up to at least a single fiber break. Each OLT operates on a unique wavelength add/drop pair. The RNs can be configured to add/drop a particular wavelength pair towards any ONU. The ONUs associate with the corresponding OLT operating on that wavelength pair. Each OLT and the associated ONUs thus form a logical PON. The selective add/drop of wavelengths towards the ONUs can be used to dynamically change the number of ONUs in every such logical PON. This can be used for dynamic inter PON bandwidth allocation for optimal bandwidth availability to the end user [2].

\section{USER PROFILES AND BANDWIDTH REQUIREMENT}

The emergence of bandwidth intensive applications has driven the need for more bandwidth to the end user and hence in the access networks to a new high. In this section we estimate the bandwidth requirement of typical residential households in the near future.

\section{A. User Categories}

Studies of typical user profiles are available for the United Kingdom [3]. It is assumed that such a profile can be used without loss of much generality in most industrialised nations. In this paper the user categories considered are adapted from [3] and are listed in Table 1.

TABLE I

USER CATEGORIES

\begin{tabular}{ll}
\hline Category & Description \\
\hline A & Single adult, retired \\
B & Two adults, retired \\
C1 & Single male, working \\
C2 & Single female, working \\
D1 & Two adults, empty nesters \\
D2 & Two adults, working \\
E & Two adults with children \\
F & Single parent \\
\hline
\end{tabular}

\section{B. Application Definitions}

Triple play is the buzzword when it comes to defining applications for the access network. This refers to voice, video and data. However gaming and peer to peer file sharing are increasing, peer to peer file sharing in particular can be extremely bandwidth intensive. Future applications can be speculative, however some applications like remote monitoring of health, remote premises monitoring and data back up seem to be very likely candidates for use by customers. Table 2 lists the typical application definitions considered in the study [3], [4].
TABLE 2

APPLICATIONS AND BANDWIDTH REQUIREMENTS

\begin{tabular}{|c|c|c|c|}
\hline Type & Application & $\begin{array}{l}\text { Downstream } \\
\text { Bandwidth } \\
(\mathrm{Mb} / \mathrm{s})\end{array}$ & $\begin{array}{l}\text { Upstream } \\
\text { Bandwidth } \\
(\mathrm{Mb} / \mathrm{s})\end{array}$ \\
\hline \multirow[t]{5}{*}{ Voice } & PSTN quality call & 0.032 & 0.032 \\
\hline & CD quality call & 0.128 & 0.128 \\
\hline & $\mathrm{DAB} / \mathrm{CD}$ quality audio streaming & 0.192 & \\
\hline & High quality digital audio streaming & 6.000 & \\
\hline & $\begin{array}{l}\text { High quality digital audio fast } \\
\text { download (at twice real time) }\end{array}$ & 12.000 & \\
\hline \multirow[t]{5}{*}{ Video } & CIF quality web conferencing & 0.320 & 0.320 \\
\hline & SDTV quality web conferencing & 0.380 & 0.380 \\
\hline & SDTV video streaming (MPEG 4) & 2.000 & \\
\hline & HDTV video streaming (MPEG 4) & 9.000 & \\
\hline & HDTV download (at twice real time) & 18.000 & \\
\hline \multirow[t]{5}{*}{ Data } & $\begin{array}{l}\text { General web browsing and email } \\
\text { download and upload }\end{array}$ & 2.000 & 2.000 \\
\hline & File down/up load (10 MB in $30 \mathrm{~s})$ & 2.667 & 2.667 \\
\hline & File down/up load (50 MB in $30 \mathrm{~s}$ ) & 13.333 & 13.333 \\
\hline & $\begin{array}{l}\text { Peer to Peer down/upload ( } 60 \mathrm{MB} \text { in } \\
30 \mathrm{~min})\end{array}$ & 0.267 & 0.267 \\
\hline & $\begin{array}{l}\text { Remote backup of data ( } 400 \mathrm{~GB} \text { in } \\
30 \text { days) }\end{array}$ & & 1.250 \\
\hline \multirow[t]{3}{*}{ Others } & Remote monitoring of health & & 0.00027 \\
\hline & $\begin{array}{l}\text { Remote premises monitoring ( } 5 \\
\text { channel SDTV quality CCTV) }\end{array}$ & & 0.69 \\
\hline & Online Gaming & 0.200 & 0.200 \\
\hline
\end{tabular}

Note: Video category calls include audio content in bandwidth calculations.

\section{User Application Profiles}

The user bandwidth demand during the day will vary depending on the application usage. The peaking of traffic requirements for typical network exchanges is around 18:00 to 21:00 hours [5], [6]. The typical applications used by the different user categories in this period are listed in Table 3. It should be noted that the applications listed are indicative of which applications can be expected in the "busy hour" from different category of users. Multiple instantiations of applications can be used in households with more than one person.

TABLE 3

USER CATEGORY AND APPLICATIONS

\begin{tabular}{ll}
\hline User & Applications \\
Cat. & \\
\hline A & SDTV quality web conferencing \\
& HDTV video streaming \\
& DAB/CD quality audio streaming \\
& PSTN quality call \\
& Remote monitoring of health \\
& Remote premises monitoring \\
& General web browsing and email download and upload \\
& SDTV quality web conferencing \\
& HDTV video streaming \\
& Remote monitoring of health \\
& Remote premises monitoring \\
C1 & High quality digital audio streaming \\
& HDTV video streaming \\
& Online Gaming \\
& File down/up load (10 MB in $30 \mathrm{~s})$ \\
& File down/up load (50 MB in $30 \mathrm{~s})$
\end{tabular}


Remote backup of data (400 GB in 30 days)

C2 High quality digital audio streaming HDTV video streaming

SDTV quality web conferencing

General web browsing and email download and upload

Remote premises monitoring

D1 SDTV quality web conferencing (up to two instances) HDTV video streaming (up to two instances) General web browsing and email download and upload (up to two instances)

Remote premises monitoring

D2 SDTV quality web conferencing (up to two instances)

HDTV video streaming (up to two instances)

General web browsing and email download and upload (up to two instances)

File down/up load (10 MB in $30 \mathrm{~s}$, up to two instances)

File down/up load (50 MB in $30 \mathrm{~s}$, up to two instances)

Remote backup of data (400 GB in 30 days)

Remote premises monitoring

CD quality call

$\mathrm{DAB} / \mathrm{CD}$ quality audio streaming (up to three instances)

High quality digital audio streaming

SDTV quality web conferencing (up to three instances)

HDTV video streaming (up to two instances)

SDTV video streaming (up to two instances)

Online Gaming (up to two instances)

File down/up load (10 MB in $30 \mathrm{~s}$ )

File down/up load (50 MB in $30 \mathrm{~s}$ )

Remote backup of data (400 GB in 30 days)

Remote premises monitoring

SDTV quality web conferencing

HDTV video streaming (up to two instances)

Remote premises monitoring

\section{Typical User applications by User Categories}

Table 4. lists the maximum bandwidth usage expected from a typical user in different user categories if the take rate for all listed applications in Table 3, is 1 . It is however expected that not all users will have such a take rate.

TABLE 4

BANDWIDTH REQUIREMENTS

\begin{tabular}{lrr}
\hline User Cat. & Downstream Max (Mb/s) & Upstream Max. (Mb/s) \\
\hline A & 10 & 1 \\
B & 11 & 3 \\
C1 & 31 & 17 \\
C2 & 17 & 3 \\
D1 & 23 & 5 \\
D2 & 39 & 24 \\
E & 62 & 37 \\
F & 18 & 1 \\
\hline
\end{tabular}

Note: Values are rounded off to integer values

The study presumes a generalised pareto distribution (shape parameter $=2$ and scale parameter $=1$ ) of applications for every user category. For households with occupancy up to 2 the pareto distribution is from location 1 . For user category D2 the distribution starts at 2 and for $\mathrm{E}$ it starts at 3 . The generalised pareto distribution is considered to assume that a majority of users use a lesser number of applications concurrently and only a minority use multiple applications concurrently. Fig. 3 illustrates the distribution of number of users as a function of concurrent applications used. The typical user demand is estimated from the kinds of applications expected and may not be the most bandwidth intensive applications.

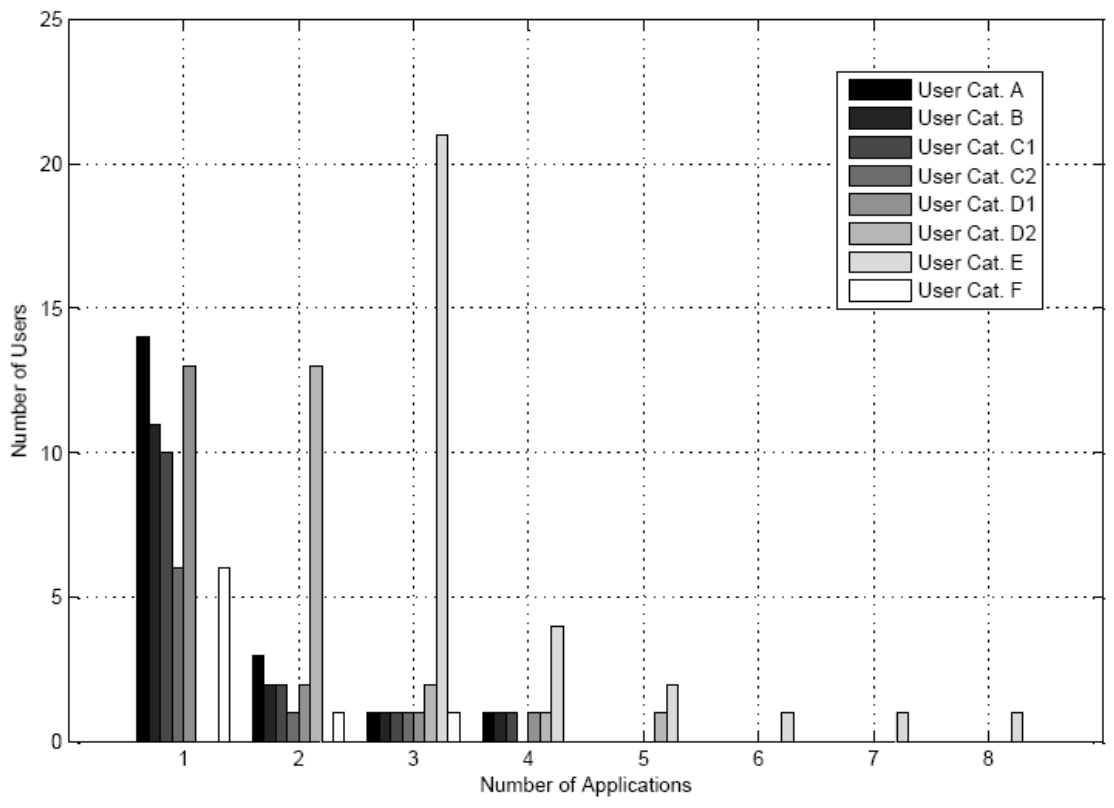

Figure 3. Generalised pareto distribution of number of users and concurrent applications used for different user categories 


\section{NETWORK CONFIGURATION}

\section{A. Network Profiles}

We consider an access network in which 128 end users have to be served. The users are assumed to be distributed over four distinct geographical regions with 32 users in each region. Two network profiles are considered; Network Profile 1 has uniform user category distributions while Network Profile 2 has a skewed distribution with clustering of high and low bandwidth users. Fig. 4 illustrates the user distribution in Network Profile 1 and Fig. 5 illustrates the user distribution in Network Profile 2. The typical network load in the downstream can be estimated based on the user profile and the application usage. The term Network group is used to indicate a group of users served by a single legacy PON deployment (of 32 ONUs).

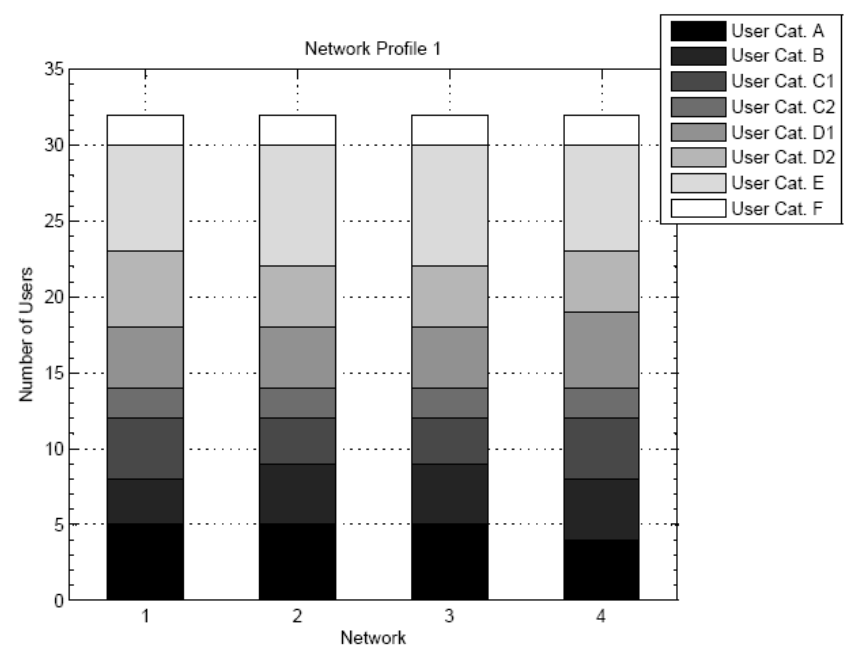

Figure 4. Network Profile 1

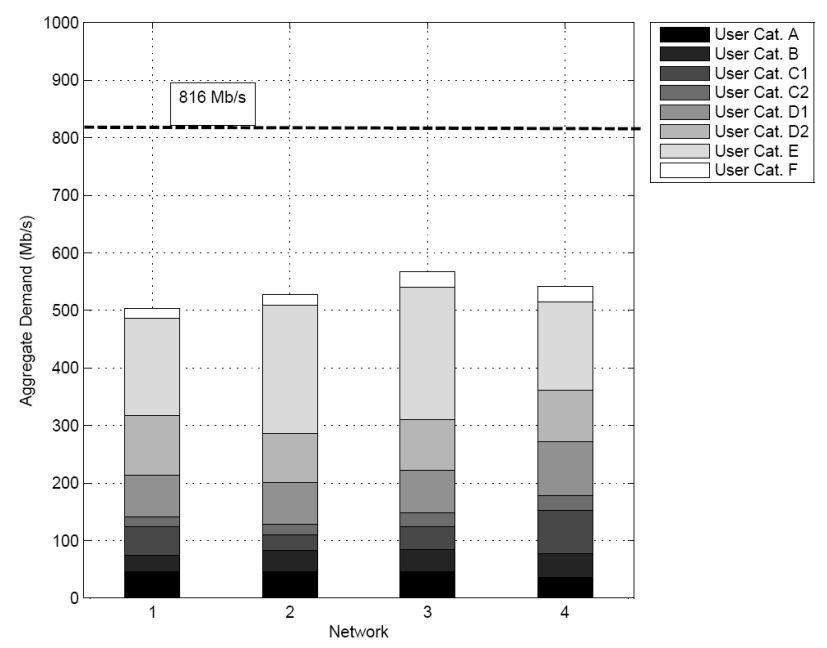

Figure 6. Bandwidth Demand in Network Profile 1

\section{B. Network Load}

The network load in the downstream is calculated for the two profiles based on the application usage. Fig. 6 illustrates the network load for Network Profile 1 and Fig. 7 illustrates the same for Network Profile 2.

\section{STATIC VERSUS DyNAMIC NETWORK CONFIGURATION}

\section{A. Static Configuration}

In this network configuration we consider four PON deployments with each supporting 32 users. The IEEE Ethernet Passive Optical Network (EPON) [7] specification is considered for providing traffic in the access network. The typical throughput that can be achieved with EPON, for 32 end users in the downstream is $816.05 \mathrm{Mb} / \mathrm{s}$ [8].

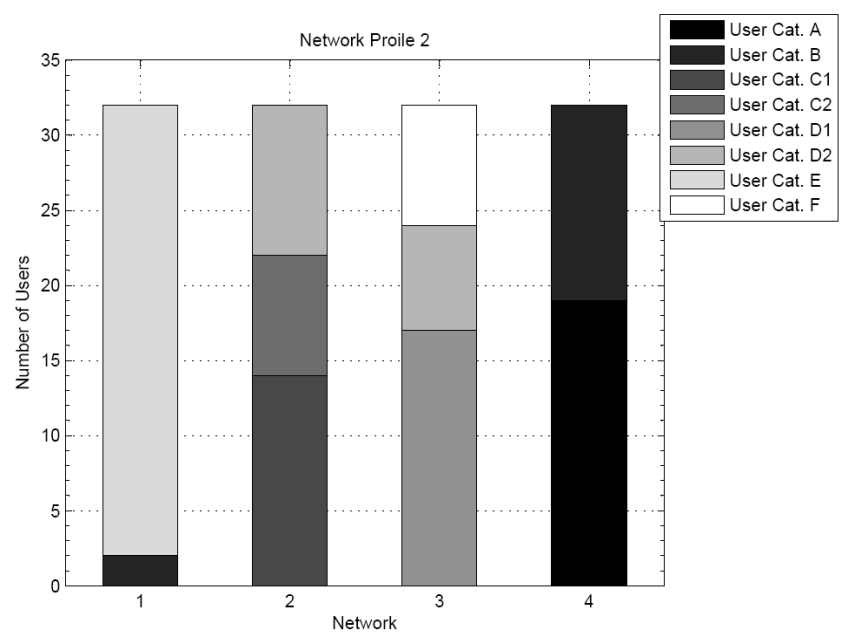

Figure 5. Network Profile 2

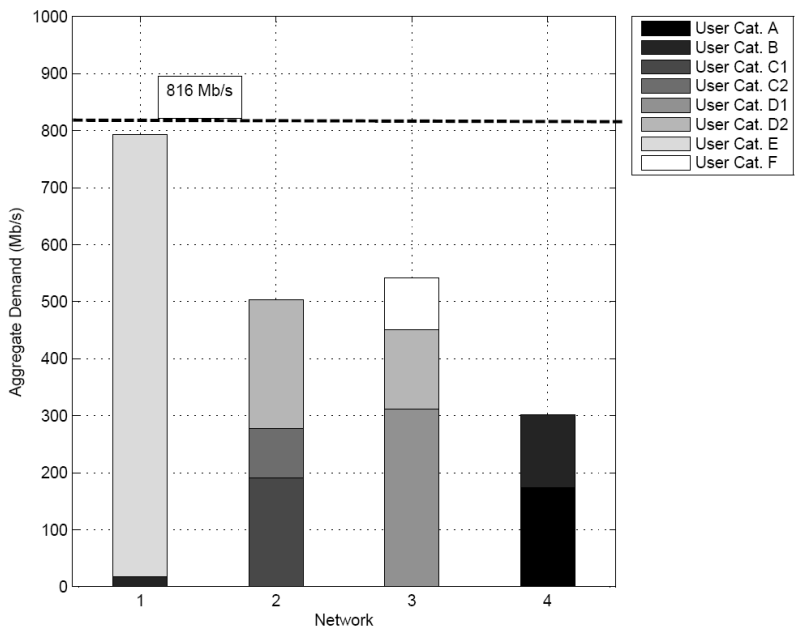

Figure 7. Bandwidth Demand in Network Profile 1 


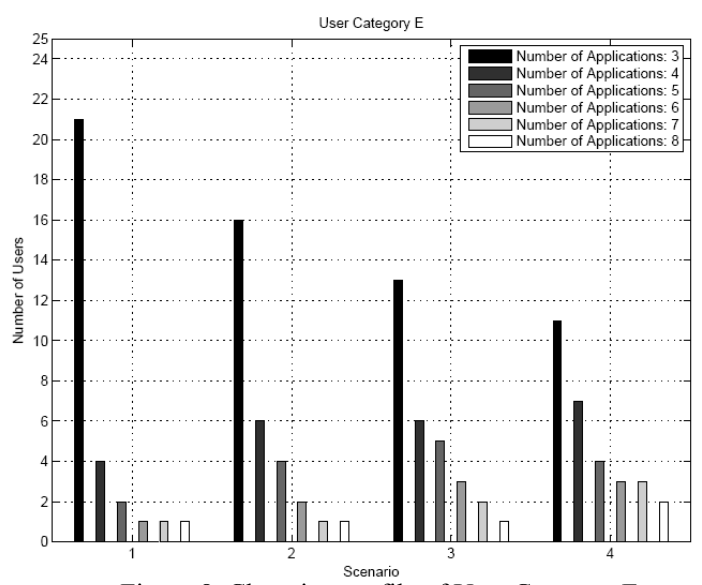

Figure 8. Changing profile of User Category E

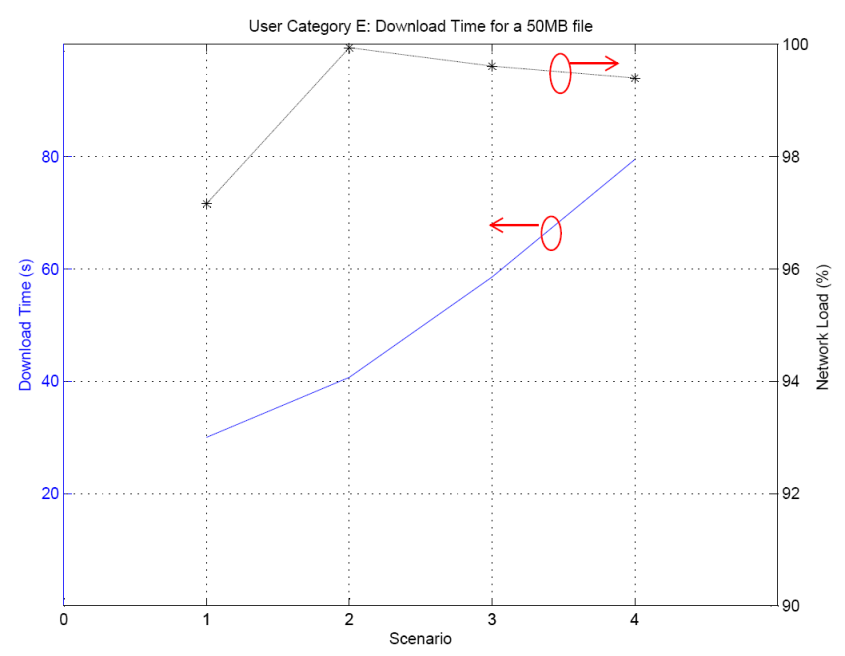

Figure 9. Download Time for a 50MB file for User Cat. E in four scenarios in Network Profile 2

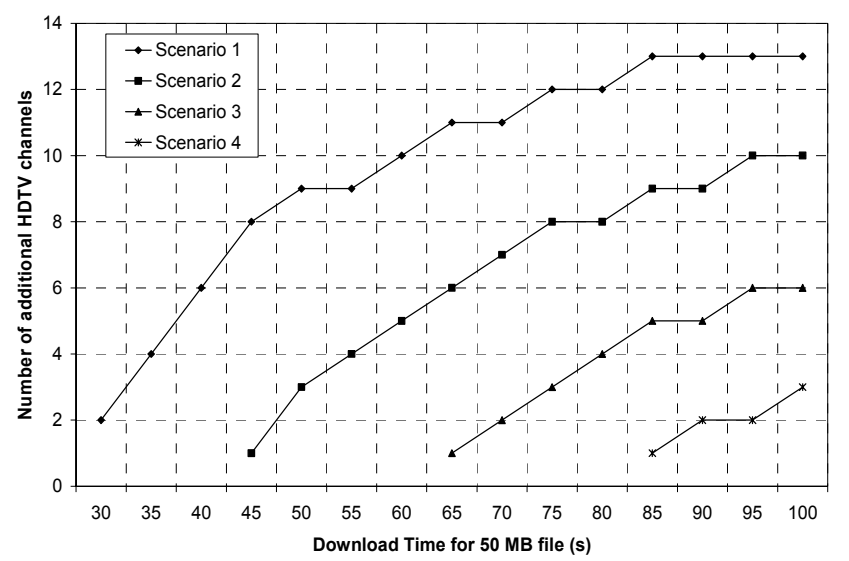

Figure 10. Download time for a $50 \mathrm{MB}$ file and available HDTV channels for User Cat. E in four scenarios in Network Profile 2

The Network profile 1 would have a typical network usage of $65.5 \%$.Network profile 2 on the other hand shows a marked skew in the loading pattern with the $4^{\text {th }}$ network group being least loaded at around $37 \%$ while the $1^{\text {st }}$ network group is loaded to around $97 \%$. Since the four groups are presumed

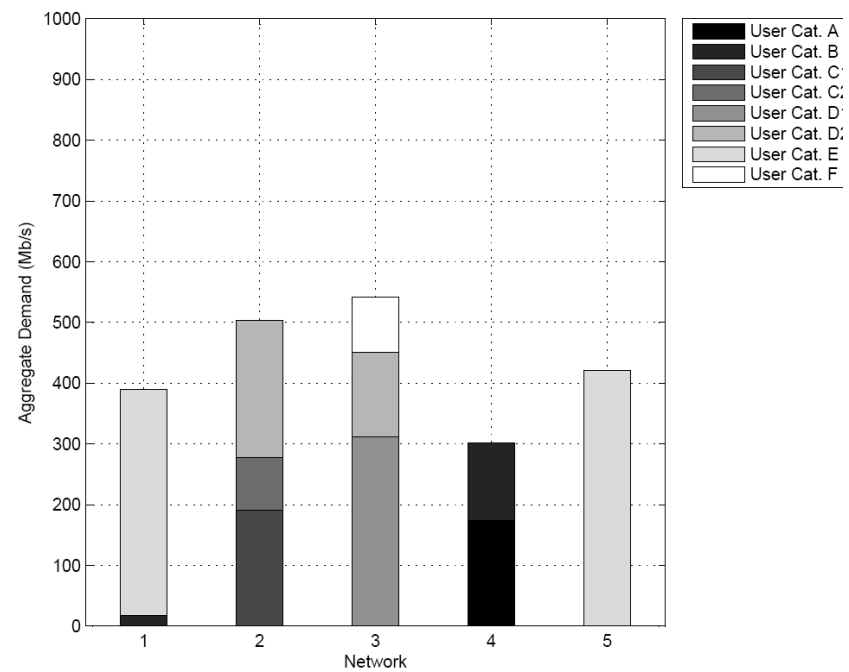

Figure 11. Network Profile 2 with five PON deployments

to be in four distinct geographical locations, each with its own PON deployment it would not be possible to re-allocate the free capacity in other network groups to a more loaded Network group.

\section{B. Sensitivity Analysis}

User Category E is a typical household with multiple residents using multiple bandwidth intensive applications. A "what if" scenario is presented by changing the distribution in the number of applications used by Category E users. Fig. 8 illustrates the change in profile number of applications used by User Category E in four different scenarios. The distribution for the four different scenarios is created by changing the scale parameter of the generalised pareto distribution from 1 to 4 . We consider Network group 1 in Network Profile 2 to quantify the performance degradation in terms of the best download time for $50 \mathrm{MB}$ files when the network is static. It is assumed that the non real time traffic such as for file down/upload is reduced to free bandwidth for streaming applications. The best download time for a $50 \mathrm{MB}$ file increases from $30 \mathrm{~s}$ to about $80 \mathrm{~s}$ in the fourth scenario. Fig. 10 illustrates additional HDTV channels that can be supported in this configuration as a function of download time for a $50 \mathrm{MB}$ file in each of the four scenarios. The metrics of an agreeable download time is beyond the scope of this paper but it is clear that in the given profile the network cannot support an increased demand from users. In a static configuration the network provider would need to commission an additional PON deployment to provide acceptable performance for customers in Network group 1 . Fig. 11 illustrates the bandwidth demand for Scenario 4 in Network Profile 2 with two PON deployments for Network group 1 (now marked as 1 and 5). The network group 1 and 5 are now less heavily loaded than earlier but come at an additional cost of another PON deployment. 


\section{Dynamic Configuration}

A dynamic configuration should allow for reallocation of unused bandwidth from other Network groups which have less load. The BBP network is visualised as a conceptual stack of quasi independent logical PONs. In such a network it would be possible to balance out the aggregate demand over all the Network groups.

\section{Concept of Dynamic reconfiguration}

A logical PON is supported with a unique wavelength pair. The number of logical PONs that are supported depend on the number of such wavelength pairs that can be used in the network. The REs which house the ROADM can drop any selected wavelength add/drop towards the ONUs. Since the ONUs are wavelength agnostic, they associate with any OLT which is operating on the particular wavelength pair. If the wavelength add/drop is changed to another pair, the ONUs will be associated with the corresponding OLT operating on that wavelength pair.

The nominal bandwidth available to the ONU depends on the number of ONUs supported by any one logical PON. If the number of ONUs increases, the nominal bandwidth available decreases and if the number of ONUs is decreased, the nominal bandwidth available increases. Fig. 12 illustrates the concept with just two colours; the "Red" and the "Blue" logical PONs with a total of 5 ONUs. The network is depicted as a conceptual two stage cross connect, the first stage is a Gigabit Ethernet (GbE) switch ( $u \times 2)$ which can switch traffic towards/from the OLTs towards the WAN while the reconfigurable network is considered as a second stage switch $(2 \times 5)$ which can switch traffic towards/from any of the ONUs to any of the OLTs. The number of ONUs supported in the "Red PON" is increased from three to four. The nominal bandwidth for the ONU in the "Red PON" now decreases while that for the single ONU in the "Blue PON" increases.

\section{E. Inter PON Bandwidth Reallocation}

The reconfiguration of the network and the consequent reallocation of ONUs to do network load balancing can be viewed as dynamic bandwidth re-allocation on an inter PON scale. To do this a Linear programming (LP) based formulation has been proposed [2]. The technique considers optimizing the bandwidth distribution to the end user subject to constraints. The triggering of any network reconfiguration will be a planned response to user requirements and it should be possible to minimise any traffic disruptions. It is also visualised that the reconfiguration will be done on a time scale in the order of tens of minutes in which the change appears quasi static to the intra PON dynamics.

Using LP based techniques the OLT-ONU association is calculated for Network group 1 in Network Profile 2 as the demand evolves from scenario 1 to scenario 4. A detailed
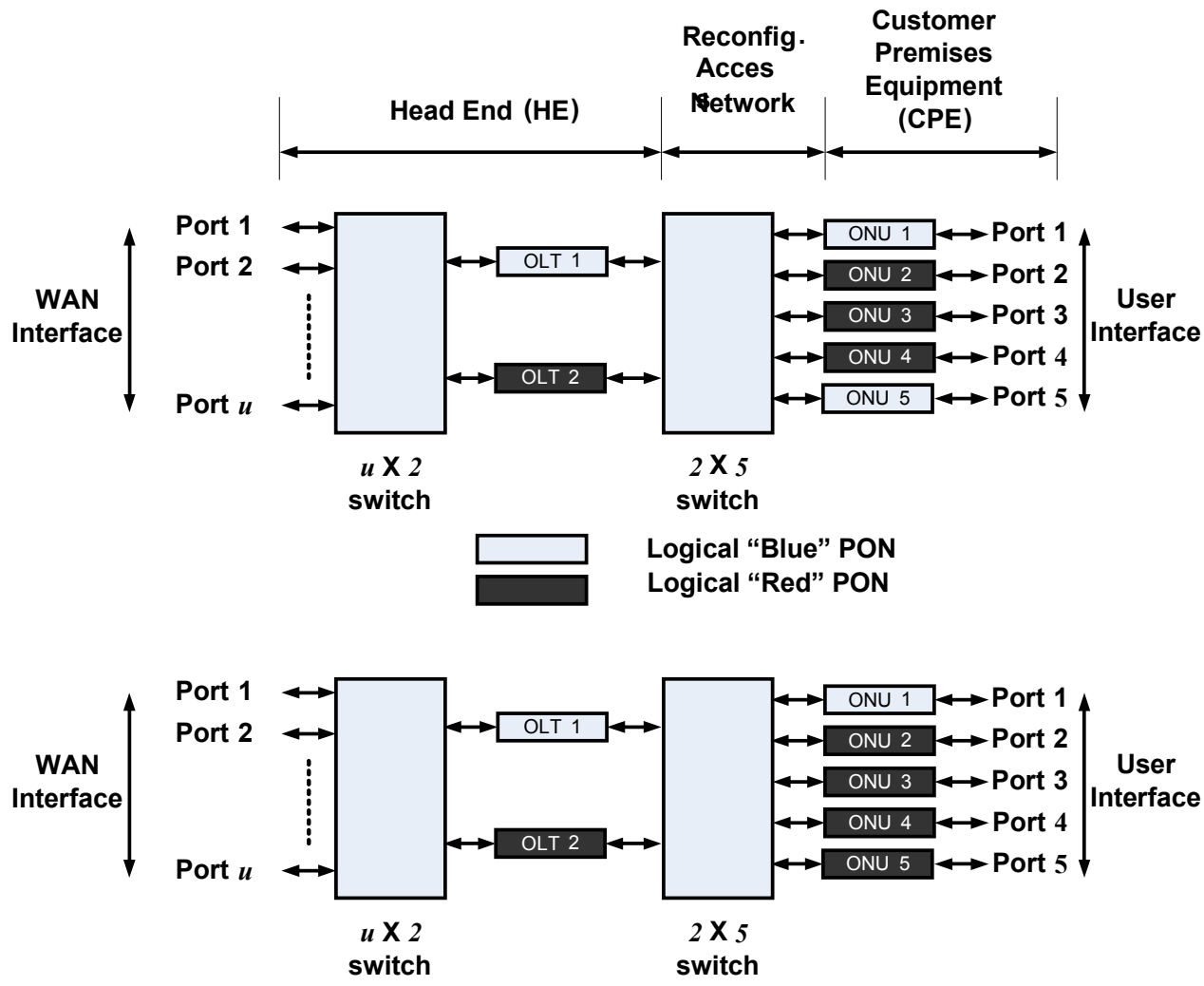

Figure 12. Concept for Inter PON redistribution of bandwidth 
representation of reallocation of the ONUs of Network group 1 is illustrated in Fig. 13. The OLTs are colour coded to represent operation on four different wavelength pairs. The ONU association to the OLTs is indicated by the colour of the box in the four scenarios. In the initial state (scenario 1) all ONUs are associated with OLT1. As the network load increases, ONUs are re-allocated to OLT2. In this example the additional capacity required for network group 1 can be met with free bandwidth from one of the other OLTs (here all the additional bandwidth requirements are met from OLT2).

\section{CONCLUSIONS}

A use case has been proposed to justify the deployment of a reconfigurable network in the access. Often network operators have no control over the user profile to which they provide service. The network might need to be over engineered to meet high capacity demands and it is not possible to provision free bandwidth available in other access networks. The illustration of the two network profiles in this paper serves the purpose of indicating that for a same aggregate user demand it might not be possible to meet the demand with similar network deployments. It is seen that if the demand distribution is skewed a static network configuration will not be able to optimise delivery of bandwidth.

The BBP concept on the other hand overlaps multiple access networks and views them as a logical stack in which load balancing can be done in an optimal manner for optimal bandwidth delivery to the end user. The use of WDM techniques is seen as an overlay over existing TDM PONs thus enabling a logical upgrade path to existing networks. While the application of EPON is demonstrated in the paper, the ITU-T Gigabit Capable Passive Optical Network (GPON) or any other TDM deployment can be used with the same concept. Use of WDM also allows for selective bitrate upgrade of certain user categories without imposing the cost on all users and it also allows operation of multiple technologies like EPON and GPON by a single operator on a single network deployment.

The reference to the network as a stack of "logical" PONs implies that the network is no longer passive. However the

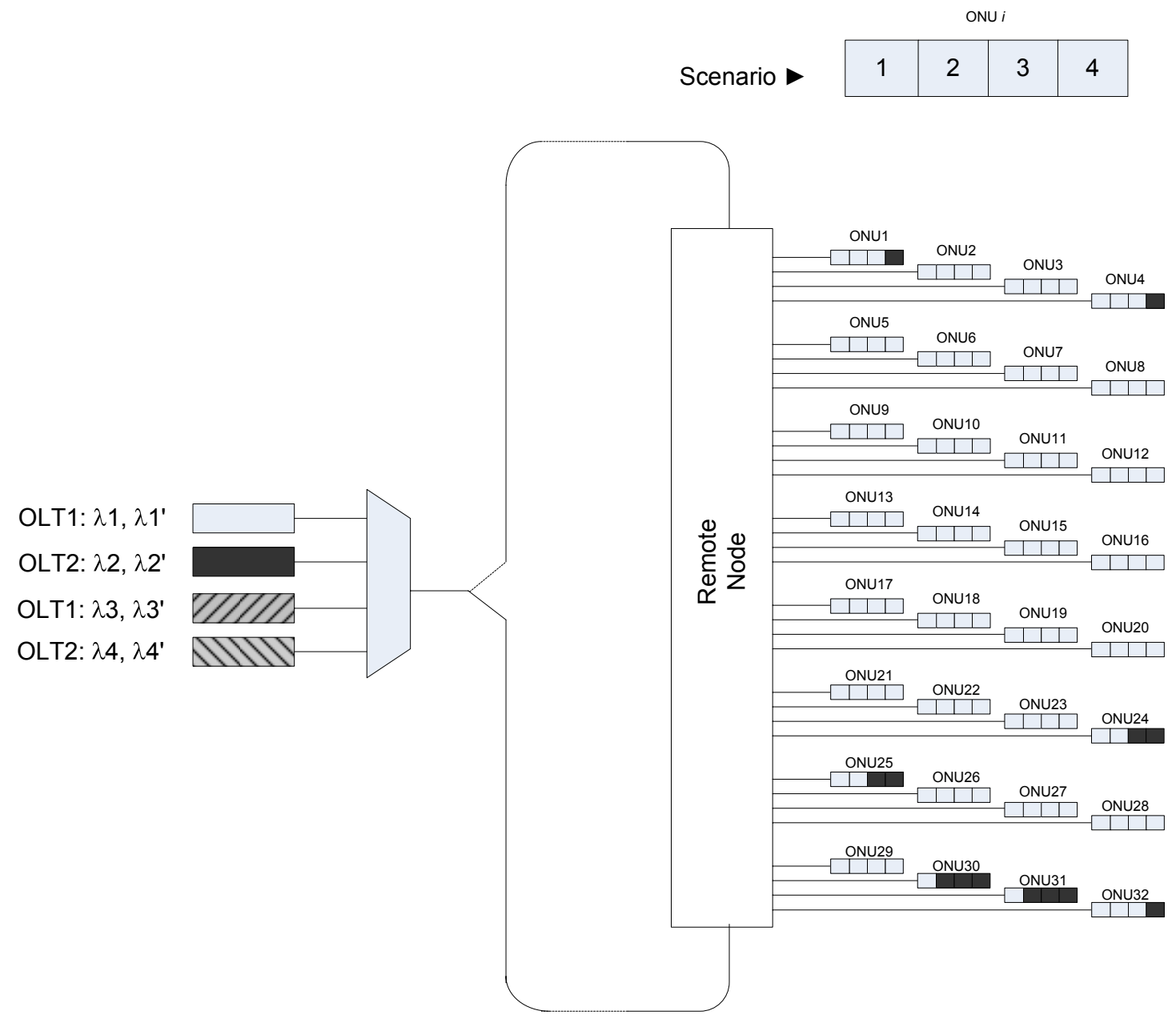

Figure 13. Illustration of ONUs in Network group 1 being served from two OLTs (OLT1 and OLT2) over four scenarios 
network retains the logical topology of PONs with a point to multipoint topology from the HE to the end user. The use of active elements in an access network is a possible argument against such deployments however the concept of an agile network would need active elements. An analysis of a costbenefit scenario of an active network, like what is depicted, vis-à-vis a passive network is beyond the scope of this paper. However it is felt within the project group that the benefits of such a dynamically reconfigurable network would be of need in next generation access networks. It is also expected that decrease in cost, decrease in power consumed in the required active components and with increased reliability of active devices some of the limitations of using such devices can be mitigated. The network concept would also cater to geographically diverse distribution of end users with a single type of network deployment. The study presents reconfiguration of a network with different categories of residential users; this can be extended to cater to more general user categories like residential and commercial users where further load balancing on a diurnal scale would be possible.

\section{ACKNOWLEDGMENT}

The work is funded by the Dutch Ministry of Economic Affairs through the BSIK Freeband Broadband Photonics project under contract BSIK 03025. The authors would like in particular to thank Mr. Gert Manhoudt of AimSys BV for his thoughtful inputs for the paper.

\section{REFERENCES}

[1] D.H. Geuzebroek, E.J. Klein, H. Kelderman, C. Bornholdt, A. Driessen, "40 Gb/s Reconfigurable Optical Add-Drop Multiplexer based on Microring Resonators," in Proc ECOC, 2005, pp 983-986.

[2] R. Roy, G. Manhoudt and W van Etten, "Bandwidth re-distribution techniques for extended EPON based multi-wavelength Networks", in Proc. ICTON, 2007, vol 4, pp 80-83.

[3] Predicting UK Future Residential Bandwidth Requirements, Broadband Stakeholder Group, www.broadbanduk.org, 2006

[4] W.Harrop, G.Armitage, "Quantifying the Broadband Access Bandwidth Demands of Typical Home Users", in Proc ATNAC, 2006

[5] Amsterdam Internet Exchange, www.ams-ix.net

[6] Munich Internet Exchange. www.inxs.de

[7] IEEE 802.3-2005, Part1-Part5, Carrier sense multiple access with collision detection (CSMA/CD) access method and physical layer specifications, IEEE Standard.

[8] G. Kramer, Ethernet Passive Optical Networks. Mc Graw-Hill, 2005.

[9] C. Lin, Broadband Optical Access Networks and Fiber to the HomeSystems Technologies and Deployment Strategies. Wiley, 2006

[10] C. Hellberg, D. Greene, T. Boyes, Broadband Network Architectures; Designing and Deploying Triple Play Services. Prentice Hall, 2007

[11] W. D. Grover, Mesh-Based Survivable Networks: Options and Strategies for Optical, MPLS, SONET, and ATM Networking. Prentice Hall, 2003. 